\title{
Stress Analysis of Crossbar of Moldboard Plough Pulled by Massey Ferguson 285 and 299 Tractors
}

\author{
Ahmad Jahanbakhshi*, Saadi Heidari Raz Darreh, Kamran Kheiralipour \\ Mechanical Engineering of Biosystems Department, Ilam University, Ilam, Iran \\ Email address: \\ ahmad.jahanbakhshi67@gmail.com (A. Jahanbakhshi) \\ ${ }^{*}$ Corresponding author
}

To cite this article:

Ahmad Jahanbakhshi, Saadi Heidari Raz Darreh, Kamran Kheiralipour. Stress Analysis of Crossbar of Moldboard Plough Pulled by Massey Ferguson 285 and 299 Tractors. Advances in Applied Sciences. Vol. 2, No. 1, 2017, pp. 11-17. doi: 10.11648/j.aas.20170201.13

Received: January 5, 2017; Accepted: January 19, 2017; Published: March 7, 2017

\begin{abstract}
Frequent failures of mechanical elements in machines and equipment due to exerted loads reveal the importance of researches and studies in this regard to optimize or redesign the parts. Practically, crossbar's pins in moldboard plough are frequently failed. So, stress analysis of that was conducted in this study by finite element method. After drawing the threedimensional model in Solid Works Software and transfer it to ANSYS Software, the constraints, boundary conditions and loads were applied on the model. Then the static analyses were done for the model. To estimate the exerted forces on the crossbar, the draft forces of Massey Ferguson 285 and 299 tractors were considered. The results of static analysis showed that the maximum static stresses based on von Mises criteria occur at the junction between the left and right pins with crossbar. The stress values based on Massey Ferguson 285 Tractor were 126 and 83.7 MPa, respectively, and based on Massey Ferguson 299 Tractor were 136 and $90.6 \mathrm{MPa}$, respectively. The obtained safety factors for the left and right pins were obtained as 1.57 and 2.36, respectively, based on the maximum draft of Massey Ferguson 285 Tractor and 1.45 and 2.18, respectively, based on the maximum draft of Massey Ferguson 299 Tractor. These results show the higher probability of failure at the left pin junction.
\end{abstract}

Keywords: Moldboard Plough, Crossbar, Static Analysis, Safety Factor, Finite Element Method

\section{Introduction}

The used equipment for cutting and pulverizing the soil, such as: rotary tiller, moldboard plough and subsoiler, are of the main tillage machinery. On one hand, this equipment consumes the highest energy compare with other agricultural machinery, and on the other hand the manufacturing process and testing of this equipment are expensive. So, optimum design of these implements is one of the most important factors to reduce the production, evaluation and application costs [1].

In most countries, moldboard plough is considered as one of the main primary tillage implements [2]. Complex shape and working depth of these implements cause the breakage of their different parts during work. One of the critical parts of moldboard plough is crossbar which is under bending loads and breakage. Breakage of the crossbar wastes the time and also costs of tillage operation. Todays, using computer aided design technique, design factors such as force, stress, deformation, optimization of machine parts and also the performance of structures under loads can be simulated and analyzed more efficiently and faster [3].

Using finite element method to calculate the stress, strain and deformation of the piece is a relatively new technique. Compared with other methods, this method has many advantages, for example: the distribution of stress - strain obtained in all the pieces can be obtained which makes it possible to identify all the critical and non-critical points in a reliable manner. Strength improvement can be conducted quickly, easily and effectively by changing properties such as the used material, the surface conditions and so on. Using this method leads to the analysis in a virtual environment without using physical models [4].

Some researches were conducted to analyses agricultural machinery by finite element method. Bahrami et al. analyzed a subsoiler with curved stem. The results of their research showed that the maximum stress happened around the small hole in the bottom of the lower stem and joint point of the stem with chassis [5]. Mouazen and Nemenyi studied the stress applied on subsoiler blade in a non-homogenous sandy- loam soil using finite element method. The results of 
their study were compared with the results of the subsoiler in soil and they concluded that the finite element method is suitable for modeling and analysis of tools in soil [6]. Bayrakceken researched on the bevel pinion shaft of bus. He resulted that high stress concentration in some parts of the shaft was the main reason for cracking [7]. Analysis of mechanical stress and soil deformation by power harrow blade showed that the highest stress and deformation occur on the tip of the harrow blades [8]. Kamali et al. analyzed a two-wheel cultivator using finite element method. The results showed that the maximum stress is obtained in joint point of tool with the cultivator chassis [9]. Jafari et al. analyzed front axle of JD 955 combine harvester under static loading. The results of their research showed that the calculated value of safety factor was too low. They stated the front axle wasn't strong enough to be installed on the harvester [10]. Hassan et al. researched on fatigue analysis of gear type hydraulic pump of JD 955 combine harvester by finite element method. They stated by considering fully reverse loading, the life gear can be estimated and critical crack growth points can be found [11]. Tarighi et al. analyzed the static and dynamic beaver of front axle housing of a tractor using finite element method. They obtained the maximum stress and safety factor according to Von-Misses criteria [12]. Aduloju et al. studied the effect of tilting of tractor front axle support. They reported that based on von Mises criteria, the safety factor of the designed component was low [13].

One of the main problems of moldboard plough is breakage of crossbar pin during work. This fracture increases the cost of maintaining and repairmen of the plough. So, mechanical analysis of crossbar under the critical working condition in order to optimize and increase the mechanical strength of the bar is necessary. Therefore, the aim of this study is to analyze the crossbar of moldboard plow by finite element method.

\section{Materials and Methods}

In the present study, a crossbar of one-way moldboard plough was considered to be evaluated by finite element method. Firstly, the cross bar was simulated in SolidWorks 2013 Software with its true dimensions. The isometric view of the model has been showed in Figure 1.

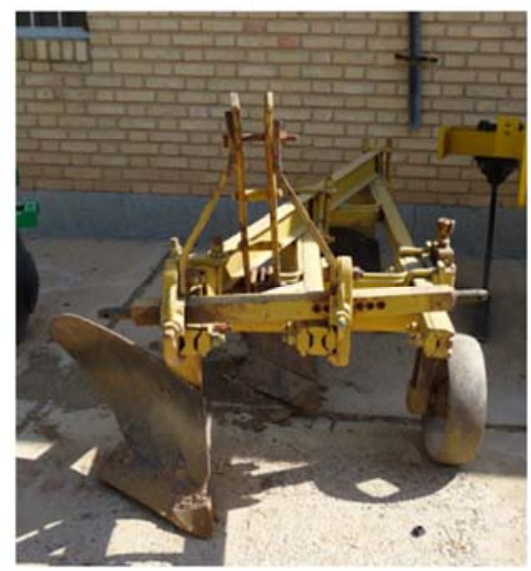

Figure 1. The isometric view of simulated model.

Then the model was imported into ANSYS 15 Software. The characters of steel (ST37) was used for modeling the crossbar of moldboard plow in the software. The details of ST37 were presented in Table 1.

Table 1. The specification of ST37 [14].

\begin{tabular}{llll}
\hline Specification & Emblem & Quantity & Unit \\
\hline Ultimate stress strength & $\sigma_{\mathrm{ut}}$ & 235 & $\mathrm{MPa}$ \\
stress yield limit & $\sigma_{\mathrm{y}}$ & 198 & $\mathrm{MPa}$ \\
Poisson's ratio & $\varepsilon$ & 0.3 & - \\
Elasticity & $\mathrm{E}$ & 200 & $\mathrm{GPa}$ \\
Density & $\rho$ & 7860 & $\mathrm{~kg} / \mathrm{m}^{3}$ \\
\hline
\end{tabular}

In order to static analysis of the model by ANSYS Software, firstly Solid Brick 10 node 187 element was selected. This element type is a three dimensional one that has 8 nodes with three degrees of freedom for each node. The model was meshed so that 51866 nodes were created (Figure 2).

After meshing, the boundary conditions of the model were applied in all respects. To consider the crossbar loading force, the maximum draft force of two types of commonly used tractors in Iran, Massey Ferguson 285 and 299, with the specifications contained in Table 2 were used.

The pins on both ends of cross bar are attached to the lower connection arms of tractor. The forces are applied on the pins when pulling the moldboard plough by the tractor. As different pins on both ends are not at the same distance from the tractor connection arms, the amount of forces acting on the crossbar pins are not equal. So, the acting force on each pin was calculated. The force direction was considered same as the tractor motion (X direction). Considering back view of the tractor, the distance between right support and right pin is less than that of left support and pin (Figure 3). 


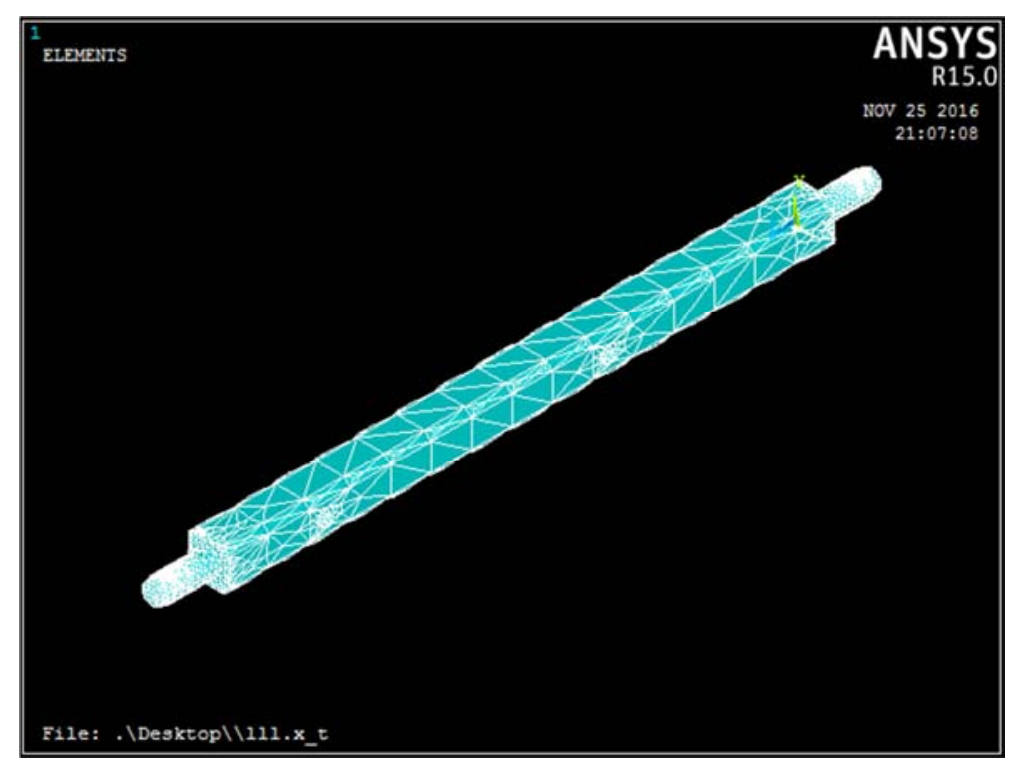

Figure 2. The meshed model.

Table 2. Technical specifications of used tractors.

\begin{tabular}{lllllll}
\hline Tractor type & Manufacturer & Engine model & Number of cylinders & Weight (kg) & Power (hp) & Maximum draft force (kN) \\
\hline MF 285 & Iran Tractor Manufacturing Co. & A4-248 & 4 & 3441 & 75 & 32.2 \\
MF 299 & Iran Tractor Manufacturing Co. & A4-244 & 4 & 4164 & 82 & 34.8 \\
\hline
\end{tabular}

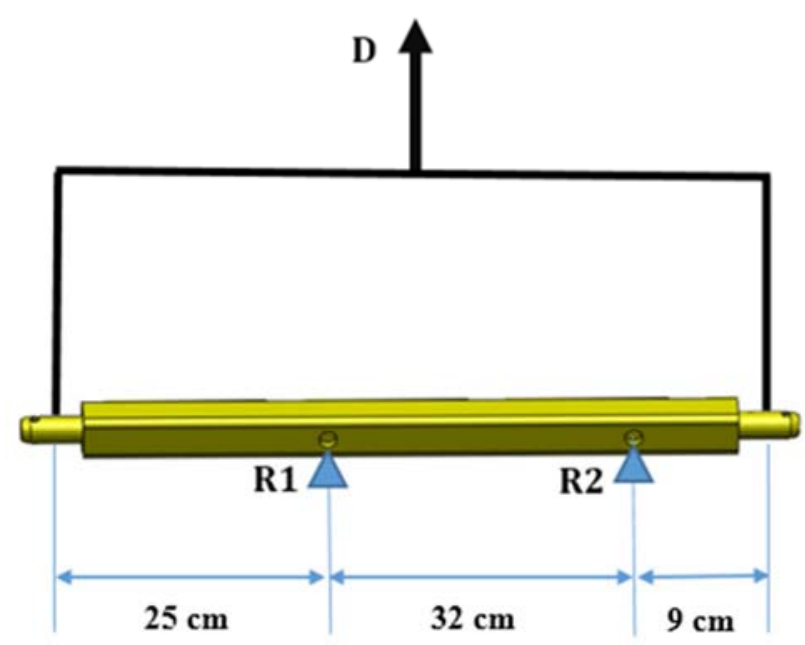

Figure 3. The supports and their distances on the crossbar of moldboard plough. $R 1$ and $R 2$ are the support reaction of left and right pins, respectively, and $D$ is the maximum draft force.

The magnitude of the support reaction of left pin $\left(\mathrm{R}_{1}\right)$ was calculated using Eq. 1:

$$
\sum \mathrm{M}_{\mathrm{R}_{2}}=0 \mathrm{D} \times 24-\mathrm{R}_{1} \times 32=0
$$

The support reaction of the right pin $\left(R_{2}\right)$ was calculated by Eq. 2 :

$$
\sum F_{x}=0 R_{1}+R_{2}=D=32200 N(M F 285), 34800 N(M F 299)
$$

$$
\mathrm{R}_{2}=\mathrm{D}-\mathrm{R}_{1}
$$

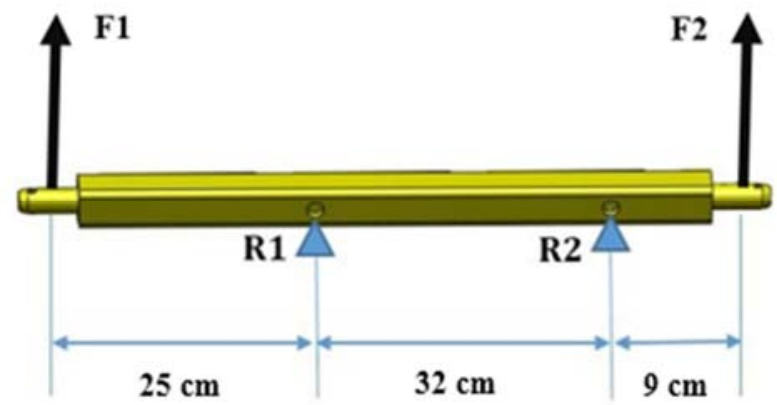

Figure 4. The exerted forces on the pins. F1 and F2 are the portions of tractor draft exerted on the left and right pins, respectively.

The magnitude of the portions of tractor draft exerted on the left and right pins were calculated using Eq. 3 and 4:

$$
\begin{aligned}
& \sum F_{x}=0 F_{1}+\mathrm{F}_{2}=R_{1}+\mathrm{R}_{2}=D F_{1}=\mathrm{D}-\mathrm{F}_{2} \\
& \sum M_{R_{2}}=0 F_{1} \times 57-\mathrm{R}_{1} \times 32-F_{2} \times 9=0
\end{aligned}
$$

The force on the anchor pin and the forces of reaction have been reported in Table 3 .

For static analysis of the crossbar, the loads were exerted on the real nods of the pins. After analysis in ANSYS Software, the amount of stresses was recorded based on the theory of von Mises criteria. Then, safety factor of cross bar in static loading was calculated using Eq. 5. [15].

$$
F S=\frac{\sigma_{y}}{\sigma_{\text {all }}}
$$

Where FS is safety factor in the static loading, $\sigma_{\mathrm{y}}$ is the yield point and $\sigma_{\text {all }}$ is the maximum stress exerted on the model. In the design of a machine part, to achieve least 
safety, the maximum amount of applied stress must be lower than the yield point of materials.

Table 3. The exerted forces $(N)$ on the anchor pin and calculated reaction forces.

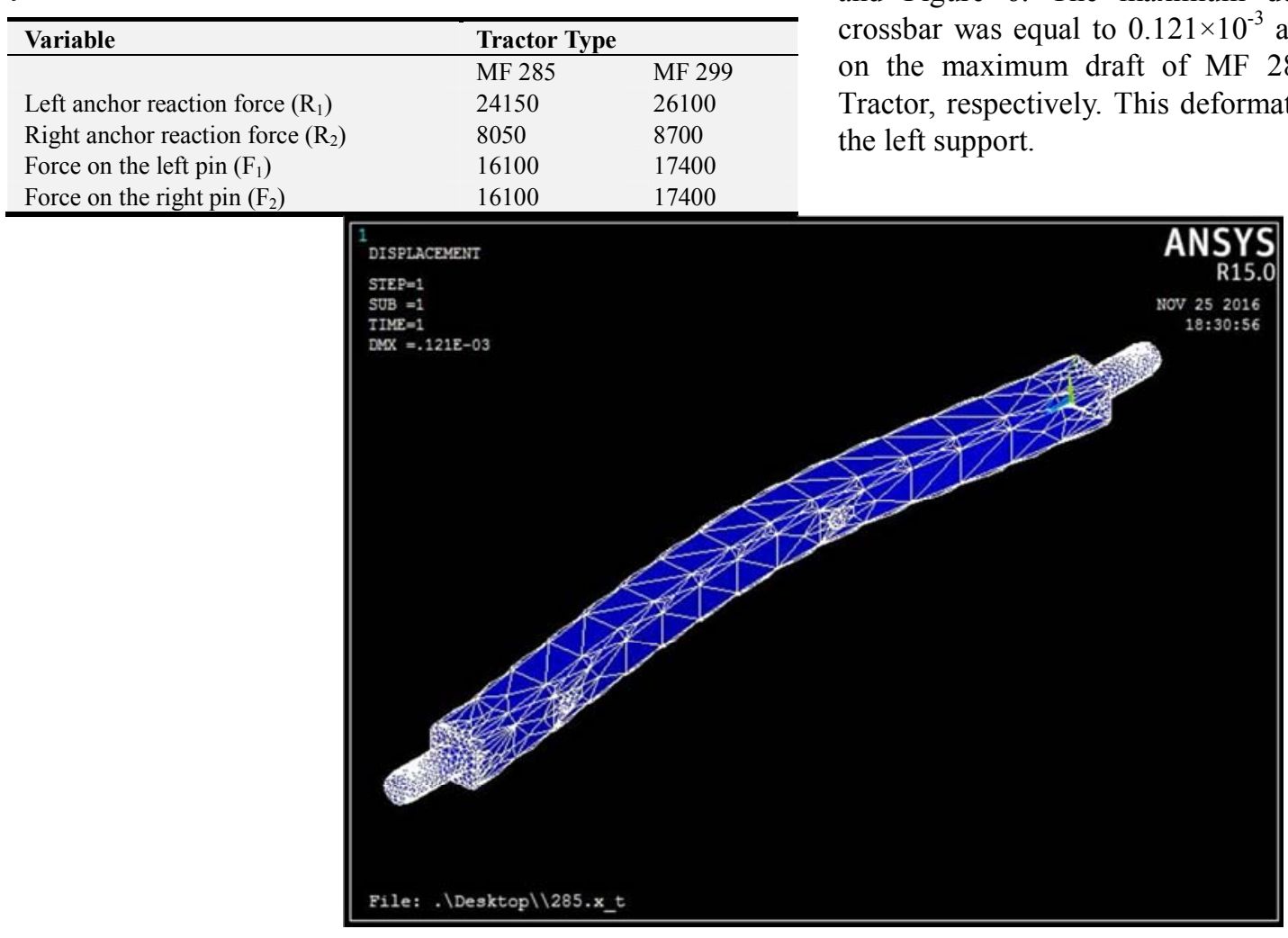

Figure 5. The deformation of the crossbar when connect to MF 285 Tractor.

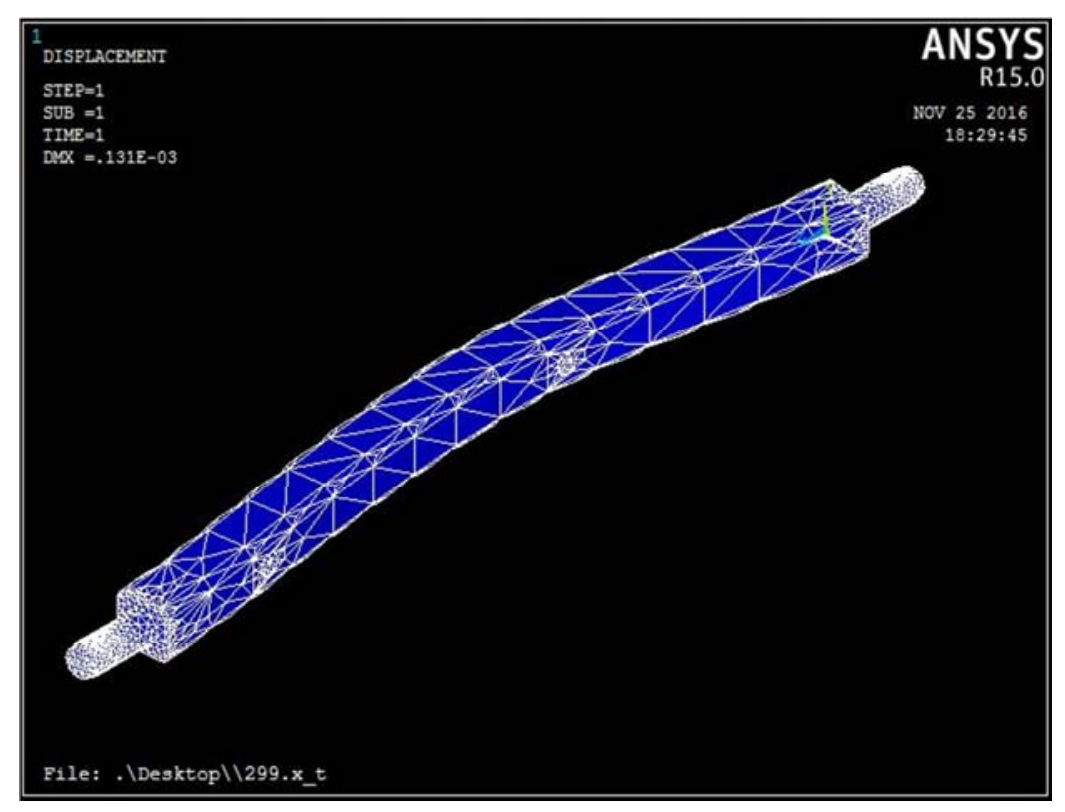

Figure 6. The deformation of the crossbar when connect to MF 299 Tractor.

Stress distribution based on von-Mises criteria in the crossbar has been shown in Figure 7, 8, 9 and 10. As can be seen in these figures, the highest amount of stress has been obtained in the pin junctions. In Figure 7 the maximum stress was shown on the right pin which is equal to $83.7 \mathrm{MPa}$ and has occurred in node number 916 and 2554 based on the maximum draft of MF 285 Tractor. The highest stress value was seen in left pin (Figure 8) that is equal to $126 \mathrm{MPa}$ and on node number 1284 and. 


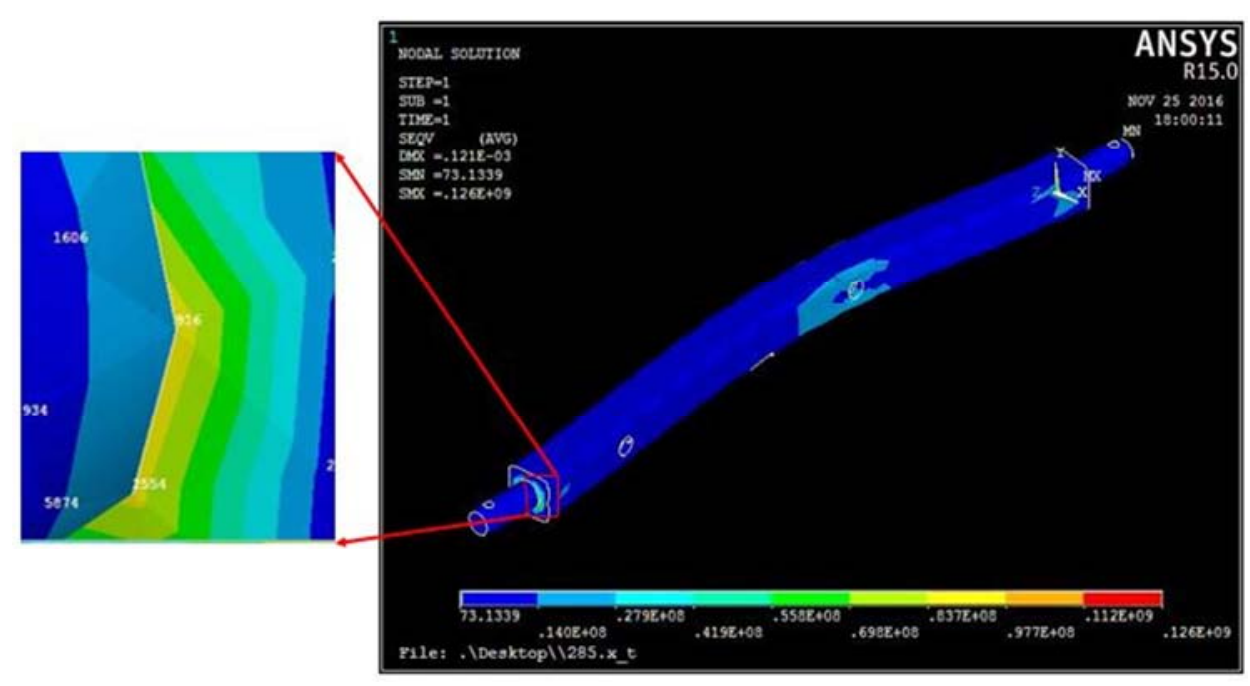

Figure 7. Stress distribution on the right pin of the crossbar when connected to MF 285 Tractor.

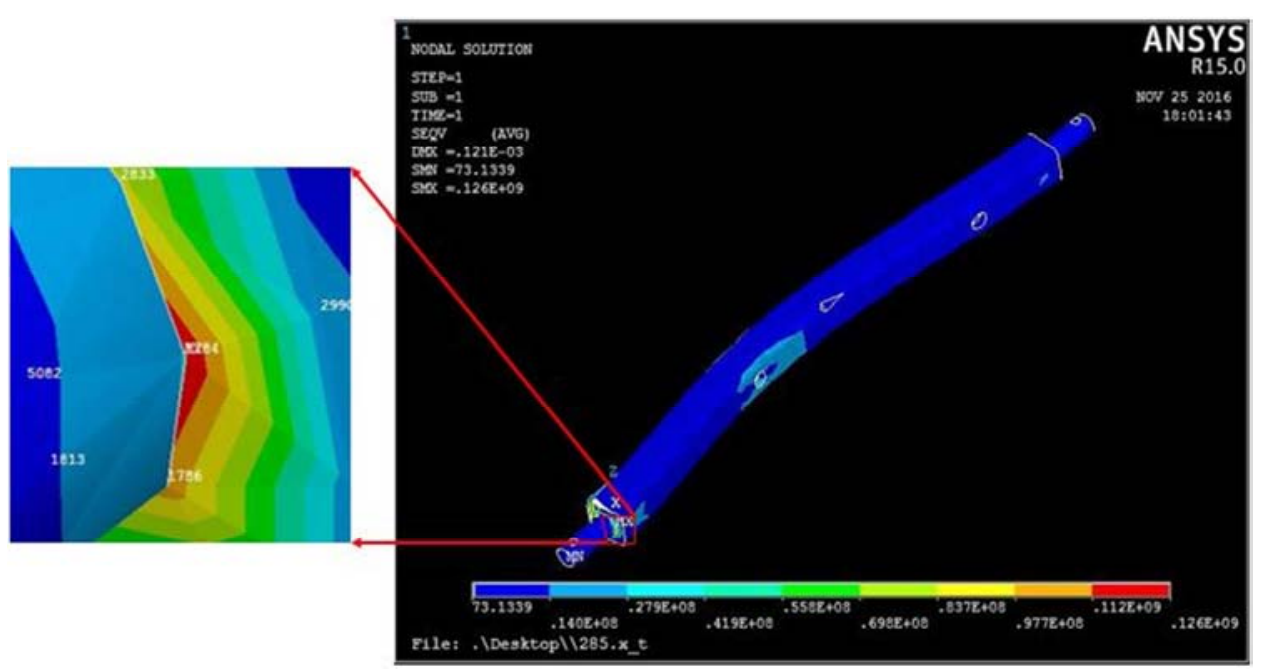

Figure 8. Stress distribution on the left pin of the crossbar when connected to MF 285 Tractor.

Based on the maximum draft of MF 299 Tractor, the maximum stress was seen on the right pin which is equal to $90.6 \mathrm{MPa}$ and has occurred in node number 916 and 2554 (Figure 9). In Figure 10, the highest stress value was seen in left that is equal to $136 \mathrm{MPa}$ and on node number 1284 .

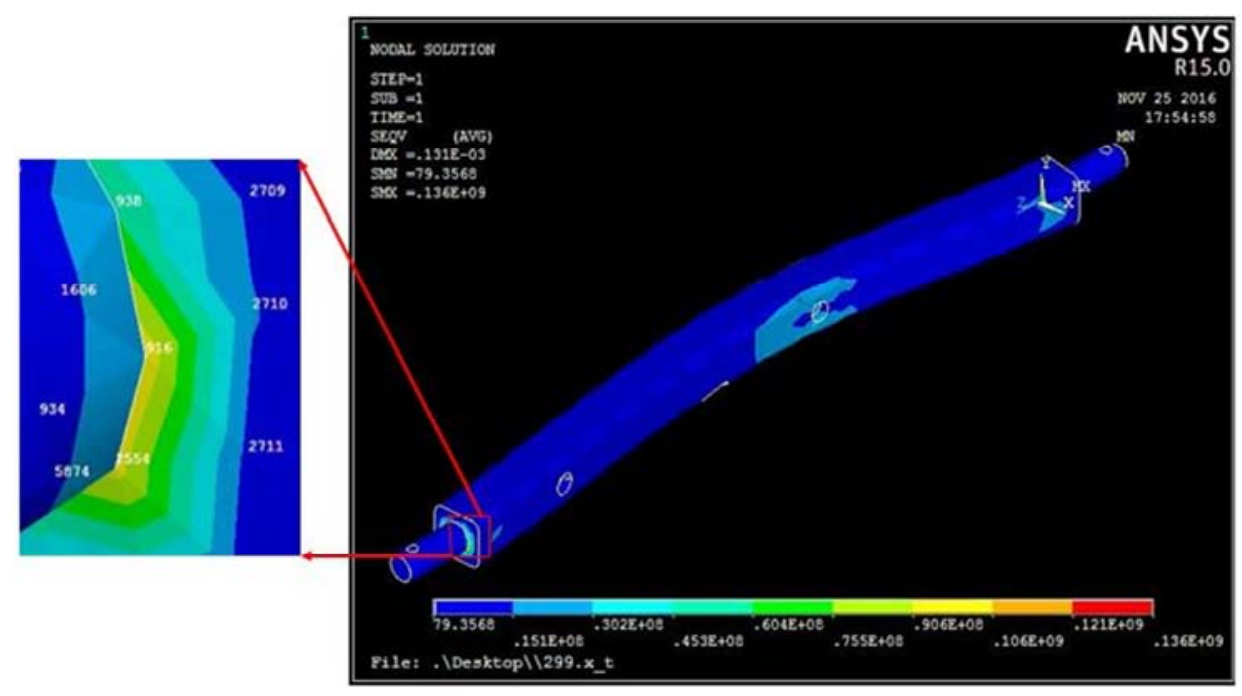

Figure 9. Stress distribution on the right pin of the crossbar when connected to MF 299 Tractor. 


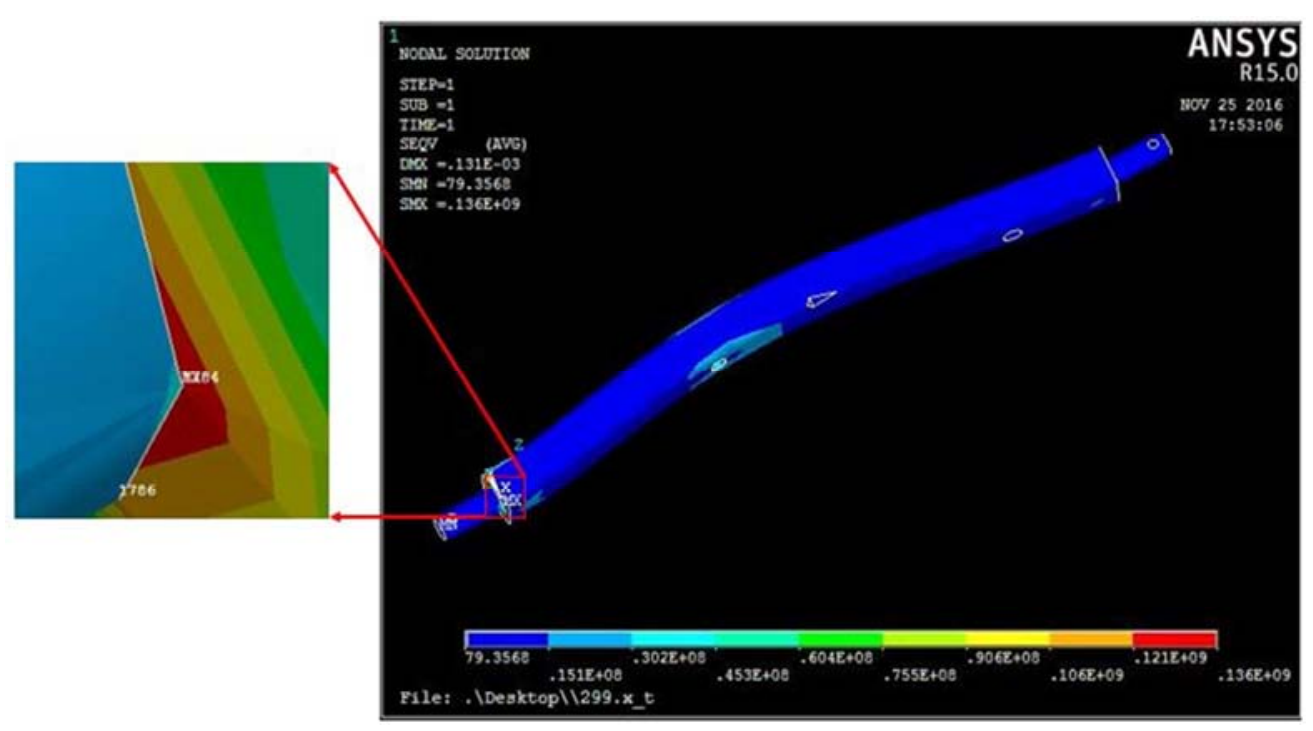

Figure 10. Stress distribution on the left pin of the crossbar when connected to MF 299 Tractor.

According to Figure 7, 8, 9 and 10, the highest stress in EM model of the moldboard plough crossbar based on vonMises criteria occurred at the junction points of the left pin. So, this analysis gave higher probability for fracture of left pin junction. This result is due to more distance between the left pin and support and therefore more force applied on that compare with right pin. Also the cross-section area of the pins is smaller than other points in cross bar. In addition, the connection angle between pin and cross bar is $90^{\circ}$ with high stress concentration factor that increase the fracture possibility.

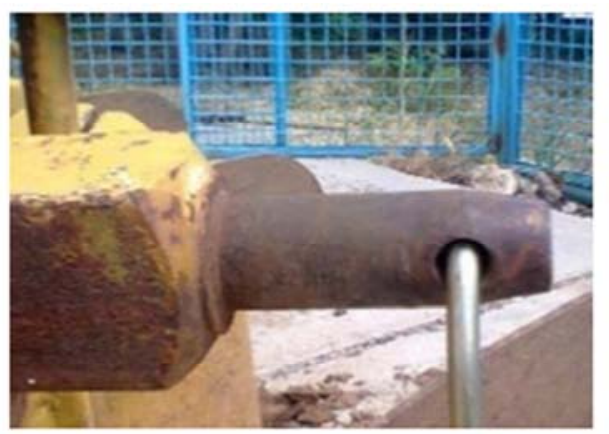

(a)
Using Eq. 5 and maximum stresses in the right and left pins, the safety factor was achieved based on the maximum draft forces of MF 285 Tractor as 2.36 and 1.57, respectively and when connected to MF 299 Tractor 2.18 and 1.45, respectively. This result indicates higher risk in left pin for failure compare with that of right pin. In practice, the left pin is fractured and then welded by machinery owners (Figure 11). So static analysis result of the present research is in agree with which practically is happened for crossbar of moldboard plough.

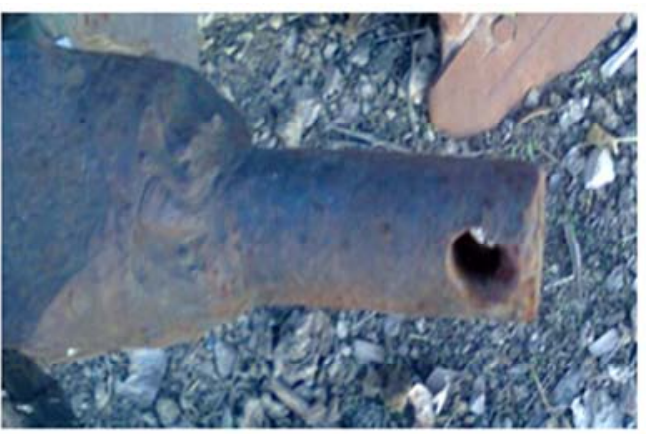

(b)

Figure 11. The left pin of crossbar, a) healthy pin and b) broken and welded pin.

\section{Conclusions}

Finite element method is widely used in engineering problems such as static and dynamic structure. By examining the static force exerted on the crossbar of moldboard plough, the maximum stress based on von-Mises criteria was obtained for left pin. The exerted force in the left pin was more than that of right pin, because left anchor had more distance to the pin. The safety factor derived from static analysis for right pin connecting point was more than that of the left one. With this result, the fracture possibility of left pin was lower than other points due to lower safety factor. Although safety factor in the left pin is more than unit, but practically, unbalanced and/or sudden loads lead to failure of left pin of crossbar.

\section{References}

[1] Zhijun, G. Zhili, Z. Zhang, Y. and Zhongli, 2009. Bionic optimization research of soil cultivating component design. Sci china sar E-Tech Sci Apr 52: 955-965.

[2] Ashrafizadeh, S. R. and Kushwaha, R. L. 2003. Soil failure model in front of a tillage tool action- A review. Presentation at the CSAE/SCGR 2003. Meeting Montreal. Quebec, July 69. 
[3] Besharati Givi, M. K. 2012. Production and Technology Engineering. First volume. First Edition. Tehran University Press. (In Persian).

[4] Mireey, S. A. Omid, M. Jafari, A. 2006. The Fatigue Analysis of Universal Tractor U650 Model in The Connecting Rod Using Finite Element ANSYS Software. New Findings in Agriculture, 1 (1). (In Persian).

[5] Bahrami, M. Javadi Kia, P. Ebrahimi, E. Bagvnd, A. Moradkhani, KH. 2012. Analysis and optimization stem volume of Subsoiler curved finite element method. The $7^{\text {th }}$ National Conference on Agricultural machinery Engineering and Mechanization, Shiraz University, Iran. (In Persian).

[6] Mouazen, A. M. and Nemenyi, M. 1999. Finite element analysis of subsoil cutting in non-homogeneous sandy loam soil. Journal of Soil and Tillage Research. 151: 1-15.

[7] Bayrakceken, H. 2005. Failure analysis of an automobile differential pinion shaft. Engineering Failure Analysis. 13: 1422-1428.

[8] Wan, J., L. Young, J. Kim, S. Kang, S. B. Shim, and J. Y. Kim. 2012. Stress analysis of blade of power harrow depending on types of soil. CIGR AGENG. Jul 8-12 Spain.

[9] Kamali, M. Rashidi, M. \& Mohammad Zamani, D. 2015. Modeling and analysis of mechanical components for tractors, two-wheel cultivator using the finite element method and software solid works simulation, Journal of Environmental Engineering Systems, 4 (2). (In Persian).

[10] Jafari, A., Khanali, M., Mobli, H., \& Rajabipour, A. 2006. Stress analysis of front axle of JD 955 combine harvester under static loading. J. Agric. Soc. Sci., 2 (3), 133-135.

[11] Hassan, H., Ali, J., Seyed, S., \& Ali, M. 2010. Fatigue Analysis of Hydraulic Pump Gears of JD 955 Harvester Combine Through Finite Element Method. Journal of American.

[12] Tarighi, J., Mohtasebi, S. S., \& Alimardani, R. 2011. Static and dynamic analysis of front axle housing of tractor using finite element methods. Australian journal of Agricultural Engineering, 2 (2), 45.

[13] Aduloju, S. C., Mgbemena, C. O., Ebhota, W. S., \& Bolarinwa, G. O. (2014). Computer Aided Structural Analysis of Axle Tilting Effect on Tractor Front Axle Support. Computer, 5 (7).

[14] Vahedian, A. 2006. Strength of Materials. written by Pierre,F and. Johnson, R. Third Edition. Publication of academic science. (In Persian).

[15] Shigley, JE, and Mischke, CR. 1989. Mechanical Engineering Design. Mcgrew-Hill Publisher. 